\title{
ANALISIS FAKTOR-FAKTOR YANG MEMPENGARUHI WISATAWAN DALAM PEMILIHAN KULINER DI KAWASAN WISATA ALAM KEMUNING
}

\author{
Liana Mangifera ${ }^{1}$, Muzakar Isa ${ }^{2}$, M. Farid Wajdi ${ }^{3}$ \\ 1,2,3 Fakultas Ekonomi dan Bisnis \\ Universitas Muhammadiyah Surakarta \\ ${ }^{1}$ Email: liana.mangifera@ums.ac.id
}

\begin{abstract}
ABTRAK
Penelitian ini bertujuan menganalisis factor-faktor yang mempengaruhi wisatawan dalam pemilihan kuliner di kawasan wisata alam Kemuning. Variabel yang digunakan adalah harga, citra restoran, kualitas makanan minuman, dan lokasi. Populasi penelitian ini adalah konsumen yang pernah melakukan wisata ke kawasan kemuning dan juga pernah melakukan pembelian makanan atau minuman. Pemilihan sampel menggunakan metode purposive sampling.Jumlah sampel yang diambil dalam penelitian ini sebanyak 94 orang responden. Penelitian ini menggunakan data primer yang diambil menggunakan wawancara terstruktur dengan bantuan kuesioner. Analisis data yang digunakan adalah analisis regresi berganda. Simpulan yang dihasilkan adalah adalah harga dan lokasi berpengaruh positif dan signifikan terhadap keputusan pembelian, sedangkan citra restoran dan kualitas makanan dan minuman berpengaruh positif tetapi tidak signifikan terhadap keputusan pembelian pemilihan kuliner di kawasan kemuning karanganyar. Lokasi paling berpengaruh dalam pemilihan tempat kuliner di kawasan wisata alam kemuning.
\end{abstract}

Kata Kunci: Keputusan Pembelian, Wisata, Kuliner

\section{ABSTRACT}

This study aims to analyze the factors that influence tourists in the selection of culinary in the natural tourist area Kemuning. The variables used are price, restaurant image, beverage quality, and location. The population of this study is the consumers who have done tours to the region kemuning and also never make a purchase food or drink. Sample selection using purposive sampling method. The number of samples taken in this study were 94 respondents. This study uses primary data taken using structured interviews with the help of questionnaires. Data analysis used is multiple regression analysis. The resulting conclusions are price and location have positive and significant effect on purchasing decision, whereas restaurant image and food and beverage quality have positive but not significant effect on buying decision of culinary election in karanganyar kemuning area. The most influential location in the selection of culinary places in the area of nature tourism kemuning.

Keywords: Purchase Decision, Tour, Culinary

\section{PENDAHULUAN}

Pariwisata berkembang sangat pesat dan sangat penting dalam meningkatkan pertumbuhan ekonomi suatu negara (Szivas,
Riley dan Airey, 2003). Sektor pariwisata merupakan sektor ekonomi yang secara natural adalah sebuah jaringan bisnis atau product bundle (Camprubi et al., 2008; Morrison 
et al., 2004). Sektor pariwisata merupakan gabungan dari beberapa produk dan jasa yang bisa diandalkan untuk memberikan sumbangan bagi perekonomian sebuah wilayah ( Samimi et al., 2011; Camprubi, et al., 2008). Perkembangan sektor pariwisata menunjukkan sektor ini terkait dengan sektor lain, misalnya ritel, fesyen, perhotelan, kuliner, budaya dan transportasi (Dwyer dan Forsyth, 2007).

Kuliner merupakan salah satu bagian terpenting dari sebuah perjalanan wisata. Wisata kuliner menjadi suatu alternative dalam mendukung potensi wisata alam, wisata budaya, wisata sejarah dan wisata bahari.(Besra,2012). Wisata kuliner juga berhubungan dengan makanan lokal dari daerah destinasi wisata. Makanan lokal adalah hal yang sangat diperlukan dari pengalaman wisata ketika dapat menyajikan kedua aktivitas budaya dan hiburan (Hjalager and Richards, 2002). Tempat makan yang strategis, yang murah dan nyaman adalah salah satu komponen terakhir dalam menentukan lokasi kuliner yang diinginkan.

Karanganyar adalah kota yang memiliki potensi wisata cukup besar dengan nilai jual yang tinggi, banyaknya produk wisata yang ditawarkan hingga menjadi sumber bisnis bagi pelaku dunia pariwisata. Wisata Alam Kemuning Kabupaten Karanganyar dikenal memiliki banyak potensi objek dan daya tarik wisata yang mampu untuk menarik wisatawan, namun tidak semua pengunjung objek wisata hanya bertujuan menikmati suasana di objek wisata, salah satu hal menarik bagi wisatawan dalam perjalanan wisata adalah kuliner. Potensi wisata di Karanganyar akan semakin berkembang dengan baik apabila didukung dengan pengelolaan yang maksimal dan pengembangan potensi wisata kuliner sebagai daya ungkit wisatawan. (Hapsari,2008).

Minat konsumen terhadap kuliner di kemuning merupakan potensi yang bisa dikembangkan dalam mendukung pengembangan dayasaing wisata kemuning. Setiap tempat kuliner memiliki daya tarik dan keunikan sendiri-sendiri, mulai dari lokasi, harga makanan yang beragam, sampai fasilitas yang disediakan. Sebagian orang memiliki kecenderungan mengunjungi tempat makan yang homogen (tidak bervariasi), hal tersebut bisa di sebabkan beberapa hal antara lain budget (anggaran belanja), jenis makanan, fasilitas, lokasi strategis dan waktu buka. Dalam pemilihan tempat kuliner di kemuning terdapat beberapa factor yang mempengaruhi seperti harga, citra merk, kualitas produk, dan lokasi.

Faktor harga, lokasi, citra perusahaan, kualitas produk merupakan factor yang dianggap mempengaruhi dalam pengambilan keputusan pembelian konsumen, hal ini diperkuat dengan penelitian Hapsari et.al (2008). Penelitian yang dilakukan Arifin et al., (2011) menegaskan bahwa lokasi berpengaruh nyata terhadap keputusan pembelian. Harga merupakan hal yang sangat penting yang diperhatikan oleh konsumen dalam membeli produk atau jasa. Jika konsumen merasa cocok dengan harga yang ditawarkan, maka mereka akan cenderung melakukan pembelian ulang untuk produk yang sama. Penelitian Fransisca ( 2010) mendukung citra perusahaan berpengaruh dalam pengambilan keputusan Pembelian.

Banyaknya faktor yang mempengaruhi konsumen dalam pemilihan tempat kuliner merupakan permasalahan yang menarik untuk di teliti. Untuk mendukung hal tersebut, maka penelitian ini bertujuan untuk mengetahui faktor-faktor yang mempengaruhi konsumen dalam pemilihan kuliner di kawasan Wisata Alam Kemuning Karanganyar.

\section{METODE PENELITIAN}

Populasi penelitian ini adalah konsumen atau wisatawan yang pernah berkunjung ke kawasan kemuning Kabupaten karanganyar. Pemilihan sampel menggunakan metode purposive sampling. Kriteria tersebut adalah masyarakat yang lebih dari 3 kali menikmati jasa wisata kemuning. Jumlah sampel yang diambil dalam penelitian ini sebanyak 94 orang wisatawan.

Penelitian ini menggunakan data primer 
yang diambil menggunakan wawancara terstruktur dengan bantuan kuesioner. Data tersebut adalah data persepsi responden tentang harga, citra restoran, kualitas produk, lokasi serta keputusan pembelian produk atau jasa di kawasan kemuning kabupaten karanganyar. Analisis data yang diggunakan adalah analisis regresi berganda, yang terdiri dari koefisien diterminan, uji simultan (uji F), dan uji hipotesis (uji t).

\section{HASIL PENELITIAN PEMBAHASAN}

Kabupaten Karanganyar merupakan salah satu kabupaten di Karisidenan Surakarta, dimana tiap wilayah Karisidenan memiliki daya tarik wisata yang menarik serta menjadi andalan untuk menunjang pendapatan daerah. Hal ini pula yang menjadi alasan bagi tiap pemerintah daerah untuk terus melakukan pengembangan dan terobosan yang baru bagi tiap produk wisata yang telah ada maupun akan ada. Kawasan kemuning merupakan lokasi wisata alam berupa perkebunan Teh yang menghampar sepanjang jalan dengan pemandangan pegunungan dan udara yang sejuk dan segar .dilengkapi restoran atau rumah makan .

Di daerah tersebut banyak terdapat rumah makan atau restoran yang menyajikan aneka menu mulai dari minuman khas aneka varian Teh,camilan, jajanan tradisional, serta masakan jawa dengan berbagai varian harga dan fasilitas yang menarik, area untuk santai menikmati udara segar dan pemandangan serta arena bermain yang sangat menarik wisatan untuk wisata kuliner. Terdapat delapan Restoran besar yang saat ini cukup banyak diminati wisatawan yaitu Bali ndeso Resto, Ndoro Donker, Dono Resto, Nova Resto, RM. $\mathrm{Mb}$. Ning Ngargoyoso, Agrowisata Kemuning Resto, Bale Branti, Omah Kodok The \& Resto Kemuning.

Sebanyak 94 orang yang menjadi responden, yang terdiri dari 33 perempuan dan 61 laki laki. Mereka berasal dari Boyolali, Sragen, Karanganyar, Sukoharjo, Surakarta, Ngawi, Purwodadi dan Semarang. Sebanyak
$43 \%$ berusia $21-40$ tahun, $25 \%$ berusia 15-20tahun, 32\% berusia diatas 40 tahun. Profesi responden terdiri dari $47 \%$ pelajar/ mahasiswa, $28 \%$ pegawai pemerintah, $25 \%$ karyawan swasta.

Pengujian asumsi klasik digunakan untuk memastikan bahwa data yang digunakan dalam kondisi yang baik. Uji ini meliputi uji normalitas, heterokedastisitas dan multikolinieritas. Hasil uji normalitas untuk mengetahui apakah data dari masingmasing variabel memiliki sebaran yang normal ataukah tidak. Uji kolmogorofsmirnov digunakan menguji normalitas data. (Ghazali, 2015). Hasil analisis menunjukkan bahwa semua nilai asymp. Sig dia ats 5\% sehingga disimpulkan data dalam penelitian ini memiliki sebaran data yang normal.

Uji Heteroskedastisitas digunakan untuk mendeteksi ada tidaknya heteroskedastisitas dilakukan dengan uji glejser, yaitu dengan melakukan regresi variabel independen terhadap absolut residual variabel dependen dalam regresi utama (Ghazali, 2015). Hasil analisis menunjukkan bahwa besarnya nilai signifikan untuk hasil uji heterokedastisitas terhadap semua variabel memiliki nilai lebih besar dari 0,05 sehingga disimpulkan bahwa semua variabel penelitian bebas dari masalah heterokedastisitas.

Uji Multikolinieritass adalah suatu keadaan di mana salah satu atau lebih variabel independen dapat dinyatakan sebagai kombinasi linier dari variabel independen lainnya. Uji multikolinieritas dilakukan dengan melihat nilai VIF dari masingmasing variabel. Jika nilai VIF lebih rendah dari 10, maka disimpulkan bahwa tidak ada multikolinieritas yang serius antara variabel independen dalam model (Ghazali, 2015). Hasil uji multikolinearitas menujukkan bahwa nilai VIF pada uji multikolinearitas variabel penelitian memiliki nilai kurang dari 10 sehingga dapat disimpulkan bahwa semua variabel penelitian tidak terjadi multikolinearitas.

Hasil analisis regresi linear berganda dapat di lihat pada tabel 1 di bawah ini. 
Tabel 1 Hasil Analisis Regresi Linier Berganda

\begin{tabular}{lccc}
\hline \multicolumn{1}{c}{ Variabel Independen } & Koefisien & t-ratio & Sig. \\
\hline Harga (X1) & 0,305 & 2,407 & $\mathbf{0 , 0 1 8}$ \\
Citra Restoran (X2) & 0,167 & 1,475 & $\mathbf{0 , 1 4 4}$ \\
Kualitas Makanan minuman (X3) & 0,181 & 1,992 & $\mathbf{0 , 1 3 9}$ \\
Lokasi (X4) & 0,443 & 4,204 & $\mathbf{0 , 0 0 0}$ \\
Konstanta $\quad=\mathbf{1 , 5 9 9}$ & & & \\
$\mathbf{R}^{\mathbf{2}}$ & $=\mathbf{0 , 6 1 5}$ & & \\
$\mathbf{F}$ & $\mathbf{3 5 , 5 3 8}$ (Sig. 0,000) & & \\
\hline
\end{tabular}

Sumber: Hasil Analisa Data (2018)

Berdasarkan tabel 1 dapat dibuat persaman regresi linear berganda sebagai berikut:

$$
\begin{gathered}
\mathrm{Y}=1,599+0,305\left(\mathrm{X}_{1}\right)+0,167\left(\mathrm{X}_{2}\right)+0,181\left(\mathrm{X}_{3}\right) \\
(0,018)(0,144) \\
+0,443\left(\mathrm{X}_{4}\right) \\
(0,000)
\end{gathered}
$$

Hasil analisis regresi linear berganda ini di atas menunjukkan bahwa Koefisien regresi variabel harga $\left(\mathrm{X}_{1}\right)$ sebesar 0,305. Setiap kenaikan 1 satuan harga makanan dan minuman, maka keputusan pembelian di kawasan kemuning meningkat sebesar 0,305. Koefisien regresi variabel citra restoran $\left(\mathrm{X}_{2}\right)$ sebesar 0,167. Setiap kenaikan 1 satuan, kegiatan perbaikan dan promosi restoran maka keputusan pembelian di kawasan kemuning meningkat sebesar 0,167 . Koefisien regresi variabel kualitas makanan dan minuman $\left(\mathrm{X}_{3}\right)$ sebesar 0,181. Setiap kenaikan 1 satuan rasa dan variasi menu maka keputusan pembelian kuliner di kawasan kemuning meningkat sebesar 0,181.Koefisien regresi variabel lokasi $\left(\mathrm{X}_{4}\right)$ sebesar 0,443. Setiap kenaikan 1 satuan kegiatan perbaikan lokasi dan lingkungan restoran di kawasan kemuning meningkat sebesar 0,443 .

Nilai $\mathrm{R}^{2}$ sebesar 0,615 . Variasi keputusan pembelian kuliner di kawasan kemuning dijelaskan oleh variabel harga, citra restoran, kualitas makanan minuman, dan lokasi sebesar $61,5 \%$, sedangkan sisanya $38,5 \%$ dijelaskan oleh variabel lainnya diluar model yang diteliti.

Hasil uji $\mathrm{F}$ menunjukkan nilai 35,538 dengan nilai sig. 0,000 . Model penelitian ini adalah tepat (fit) dan harga, citra restoran, kualitas makanan minuman, dan lokasi secara simultan mempunyai pengaruh signifikan terhadap keputusan pembelian di kawasan kemuning.

Hasil uji $t$ untuk variabel harga menunjukkan nilai t sebesar 2,407 dengan nilai sig 0,018. Variabel harga $\left(\mathrm{X}_{1}\right)$ berpengaruh positif dan signifikan terhadap keputusan pembelian di kawasan kemuning. Hasil uji t untuk variabel citra restoran menunjukkan nilai t seebsar 1,475 dengan nilai sig 0,144. Artinya variabel citra restoran $\left(\mathrm{X}_{2}\right)$ berpengaruh positif tetapi tidak signifikan pada alpha 5\% terhadap keputusan pembelian di kawasan kemuning. Hasil uji t untuk variabel kualitas makanan minuman menunjukkan nilai t 1,992 dengan nilai sig 0,139 . Artinya variabel kualitas produk $\left(\mathrm{X}_{3}\right)$ berpengaruh positif tetapi tidak signifikan pada alpha 5\% terhadap keputusan pembelian di kawasan kemuning. Hasil uji t untuk variabel lokasi menunjukkan nilai $t$ 4,204 dengan nilai sig 0,000 . Artinya variabel harga (X1) dan lokasi (X4) berpengaruh positif dan signifikan pada alpha 5\% terhadap keputusan pemilihan kuliner di kawasan kemuning.

Dari hasil analisis diatas Lokasi kuliner di kawasan kebun teh kemuning berpengaruh positif dan paling signifikan terhadap keputusan pemilihan kuliner bagi wisatawan. Penelitian yang dilakukan Arifin et al., (2011) menegaskan bahwa lokasi berpengaruh nyata terhadap keputusan pembelian. Bahkan hasil penelitian Pecotić, et al., (2014) mengungkapkan, bahwa konsumen bersedia membayar lebih mahal untuk memperoleh lokasi dan kondisi yang lebih baik. Lokasi restoran merupakan pilihan utama yang 
mempengaruhi konsumen dan membuat keputusan pemilihan kuliner. Selain tempat yang strategis, fasilitas dan sarana penunjang wisata seperti arena bermain, spot-spot khusus untuk selfi yang saat ini paling digemari wisatawan

Faktor harga berpengaruh positif dan signifikan terhadap keputusan pemilihan tempat kuliner. Hal ini menunjukkan dengan semakin terjangkaunya harga yang ditawarkan akan meningkatkan keputusan pembelian konsumen. Responden akan mempertimbangkan harga yang sesuai dengan daya belinya. Kuliner dengan harga terjangkau dengan daya beli konsumen akan semakin diminati konsumen, hal ini didukung oleh penelitian

Kualitas makanan minuman berpengaruh positif terhadap keputusan pembelian kuliner tetapi tidak signifikan. Penelitian yang penulis lakukan relevan dengan penelitian lainnyayang dilakukan oleh Ghanimata (2010) menyatakan bahwa variabel kualitas produk berpengaruh positif terhadap keputusan pembelian. Selanjutnya penelitian lainnya yaitu yang dilakukan oleh Prasetyo (2015) dengan judul Pengaruh Kualitas Produk terhadap Keputusan Pembelian di Warung Bambu di Tembalang. Hasil penelitian menyatakan bahwa kualitas produk memberikan pengaruh terhadap keputusan pembelian pada Warung Bambu di Tembalang. Dalam hal ini kualitas produk yang bagus akan memberikan pengaruh pada keputusan pembelian.

Citra Restoran memiliki peran dalam mempengaruhi keputusan pembelian konsumen. Popularitas nama restoran serta kemampuan perusahaan dalam melayani dan memenuhi kebutuhan konsumen sangat menentukan bagaimana kesan masyarakat terhadap citra perusahaan tersebut. Restoran atau rumah makan yang memiliki citra baik produk-produknya cenderung lebih disukai dan mudah diterima dari pada perusahaan yang memiliki citra kurang baik atau citra yang netral. Citra restoran seringkali dijadikan acuan oleh konsumen untuk memutuskan keputusan pembelian ketika konsumen tersebut tidak memiliki pengalaman atau pengetahuan akan suatu produk. Hasil pengujian menunjukkan bahwa citra perusahaan mempengaruhi secara positif terhadap keputusan pemilihan kuliner, Ndoro Dongker merupakan resto and café yang cukup popular pilihan konsumen, meskipun harga makanan dan minuman disana cenderung mahal.

\section{PENUTUP}

Simpulan penelitian ini adalah harga dan lokasi berpengaruh positif dan signifikan terhadap keputusan pembelian, sedangkan citra restoran dan kualitas makanan minuman berpengaruh positif tetapi tidak signifikan terhadap keputusan pembelian. Lokasi restoran merupakan pilihan utama yang mempengaruhi konsumen dan membuat keputusan pemilihan kuliner. Selain tempat yang strategis, fasilitas dan sarana penunjang wisata seperti arena bermain, spot-spot khusus untuk selfi yang saat ini paling digemari wisatawan.

Implikasi teoritis penelitian ini adalah menguatkan berbagai penelitian terdahulu dimana harga dan lokasi merupakan faktor dominan yang mempengaruhi keputusan pembelian. Implikasi manajerialnya adalah pentingnya mempertimbangkan lokasi dalam pengembangan wisata kuliner kedepan dan penetuan harga yang sesuai dan mengoptimalkan keberadaan lokasi sehingga dapat bersaing dengan lokasi wisata lainnya.

\section{DAFTAR PUSTAKA}

Anis, Liya Monalisa. 2015. Pengaruh kualitas produk terhadap internasional Brand Image serta dampaknya terhadap keputusan pembelian. Jurnal Administrasi Bisnis (2015), Vol. 28, No. 2, November 2015. 
Anwar, iful. 2015. Pengaruh harga dan kualitas produk terhadap keputusan pembelian "Bunchbead Kota Malang". Jurnal Ilmu dan Riset Manajemen. Vol. 4, No. 12 (2015). ISSN: 2461-0593

Baron, R.M. and Kenny, D.A. 1986. The moderator-mediator variable distinction in social psychological research: Conceptual, strategic, and statistical considerations. Journal of Personality and Social Psychology. 51(6): 1173- 1182.

Ghanimata, Fifyanita dan Mustafa Kamal, 2012.Analisis Pengaruh Harga, Kualitas Produk, dan Lokasi Terhadap Keputusan Pembelian. Semarang: Universitas Diponegoro.

Gilaninia, Shahram dan Seyyed J. Mousavian. 2011. The Investigation and Analysis Impact of Brand Image in Iran. African Journal of Business Management, (6)25: 75487556

Hair, Joseph F. 2010. Multivariate Data Analysis. Fifth Edition. Jakarta: Gramedia Pustaka Utama.

Lin, Nan-Hong dan Bih-Syah Lin. 2007. The Effect of Brand Image and Product Knowledge on Purchase Intention Moderated by Price Discount. Journal of International Managements Studies, 121 132. Oentoro, Deliyanti. 2010. Manajemen Pemasaran Modern. Yogyakarta: LaksBang Pressindo.

Lukman, Marco Dirgahadi. 2014. Analisis Pengaruh Ekuitas Merek Terhadap Keputusan Pembelian dan Kepuasan Konsumen Produk Teh Botol Sosro Kemasan Kotak. Jurnal Administrasi Bisnis (2014), Vol.10, No.1: hal. 64-81, (ISSN:0216-1249).

Nisfiana, Dewi Nurun. 2009. Pengaruh kualitas produk terhadap kepuasan konsumen dalam membeli daging sapi (Studi pada konsumen depot daging Mubarokah. Jurnal Manajemen Fakultas Ekonomi Universitas Negeri Malang. Rs 658.8342 NIS p.

Peter, J. Paul dan Jerry C. Olson. 2000. Consumer Behavior. Perilaku konsumen dan Strategi Pemasaran. Jilid 2. Edisi 4. Diterjemahkan oleh: Damos Sihombing. Jakarta: Erlangga.

Susanto, Andhika H. 2013. The Influence Of Customer Purchase Decision On Customer Satisfactionand It's Impact To Customer Loyalty. Jurnal EMBA, Vol.1 No.4 Desember 2013.

Xian, Gou Li, dkk. 2011. Corporate-, Product-, and User-Image Dimensions and Purchase Intentions. 